\title{
The effect of cane length and step height on muscle strength and body balance of elderly people in a stairway environment
}

\author{
Zi Ying Li and Chinmei Chou
}

\begin{abstract}
Background: It has been reported that $75 \%$ of stairway accidents occur while descending stairs. Using a cane can help to prevent older people and those with limited mobility from falling. However, studies have shown that two-thirds of older cane users use a cane that is longer than the recommended length, which may cause unnecessary muscular loads. This study aims to assess balance and muscular load in older people descending different height steps with different cane lengths.
\end{abstract}

Methods: Nine participants (5 males and 4 females) aged over 65 years participated in this study. Cane length and stair height were independent variables. Electromyography signals were recorded from the biceps brachii of the arm that usually held the cane and from both gastrocnemius muscles. In addition, the center of pressure (COP) was assessed as an indicator of balance in older people descending a step.

Results: Descending from higher steps resulted in the use of greater arm and leg strength at the time of first foot contact. However, cane length did not affect any of the root mean square values. In addition, the CoP Stabilometric Parameters showed that mean distance, antero-posterior mean distance, total excursions, antero-posterior total excursions, mean velocity, and antero-posterior mean velocity were significantly affected by step height, but not by cane length.

Conclusions: If cane length is within the currently suggested range, then it has little effect on the force load on the arm and legs when descending a step. Step height has a greater effect than cane length on the strategies used by older people to maintain stability.

\section{Background}

As people grow older, they experience functional declines in movement, consciousness, and cognition [1,2]. Agerelated declines in movement result from changes in muscle tissue, including reduction in the quality, quantity, size, and cross-sectional area of the skeletal muscles [3]. Muscle quality and quantity decrease by approximately $30 \%$ to $40 \%$ from age 50 to 80 years $[4,5]$. This phenomenon often leads to difficulty walking, changes in gait, and an increased risk of falling, which is a common cause of death in older people. Many studies have examined the relationship between aging and falls [6-8]. The frequency of falls increases with aging, reaching $30 \%$ to $40 \%$ after 60 years of age [9]. One study of older subjects in the United

* Correspondence: shu.kinmei@gmail.com

Department of Industrial Engineering \& Management, Yuan Ze University, 135 Yuan-Tung Road, Chung-Li 32003, Taiwan ROC
Kingdom and the United States showed that falls were the main cause of accidental death in older people [10], and approximately one-third to one-half of older people fall down stairs once a year [11-13]. Additionally, another investigation showed that $75 \%$ of stairway accidents occurred while descending stairs [14], with a 3:1 hazard ratio between walking down and walking up stairs.

Using a cane can reduce the risk of falling, while also reducing pressure on the lower limbs [15]. Additionally, using a cane is an ideal means of improving the confidence of older people during walking [16]. The correct use of a cane can offset $20 \%$ to $30 \%$ of an individual's body weight [17]. However, although recommended cane lengths result in only $20^{\circ}$ to $30^{\circ}$ of elbow flexion, it has been reported that two-thirds of older cane users use a cane that is too long [16]. 
Excess cane length inhibits the transfer of arm strength or body weight to the cane, causing unnecessary pressure on the triceps. It can also increase elbow flexion and lead to an improperly raised shoulder. In contrast, a shorter cane length can cause the user to lean forward while standing or walking. In short, a cane of the wrong length will make the user feel uncomfortable and significantly increase energy expenditure $[15,16]$. Research indicates that the proper cane length is either the distance from the ground to the greater trochanter or the distance from the ground to the wrist crease $[15,18,19]$.

There is considerable disagreement over the relationship between cane length and usage and fall occurrence [18]. Experiments targeted on different populations, genders, and ages using a variety of cane lengths in different situations have failed to provide definitive results. Jones et al. [20] measured participants' heart rates to evaluate the physiological effects of different cane lengths (Type 1: from floor to greater trochanter, average: $83.1 \mathrm{~cm}$; Type 2: from floor to distal wrist crease, average: $78.6 \mathrm{~cm}$; Type 3: the individual's Height $(\mathrm{cm}) \times 0.45+0.087(\mathrm{~m})$, average: 79.7 $\mathrm{cm})$; their results showed no effect of cane length on heart rate. Another study targeted stroke patients [21]; the participants were divided into two groups based on whether their arm length was shorter or longer than 50\% of their height and both groups used the same length canes (from floor to greater trochanter). The results indicated that there was more pressure on the heels of the feet in the group with shorter arm length [21]. To date, there is no definitive evidence for the correct cane length for older people during walking on a level surface. Moreover, research on walking down stairs with a cane has been limited, despite the high risk of the stair environment. If older people use a cane improperly, it might increase pressure on the body and even lead to falls with potentially serious consequences. Thus, the purpose of this study was to determine the effects of various cane lengths on balance and muscle loading in older people when descending steps of different heights. Specifically, we tested the following two hypotheses, i) in older persons, the use of a cane for descending from a high step may result in smaller muscle loads and better balance than level walking without a cane, and ii) different cane lengths will affect balance and muscular loads when descending a step.

The results will offer older people some guidelines for proper cane length selection under a variety of conditions, and as a result may help them feel more comfortable while walking and descending stairs.

\section{Methods}

\section{Study design and participants}

The participants in this cross-sectional study were recruited between October and December 2013 from the Suang-Lien Elderly Center in New Taipei City, Taiwan.
Five males and four females participated in this study. Their mean age was $82.78 \pm 7.66$ years, height was $160.89 \pm 8.82 \mathrm{~cm}$, and weight was $60.50 \pm 12.87 \mathrm{~kg}$. Six of the participants routinely used a cane and three of these had osteoarthritis. The other participants occasionally used a cane (Table 1). All participants had functionally normal eyesight, either with or without corrective lenses. Any potential participants who had a disease that affected balance were excluded. Prior to inclusion in the study, prospective participants were assessed using the Berg Balance Scale; only those with scores $\geq 24$ were included in the study. All participants gave their written informed consent and all experimental protocols were approved by the institutional review board of the Research Ethics Office of National Taiwan University.

\section{Variables}

The independent variables in this study were cane length and step height. Three cane lengths were tested as follows: the length of Cane 1 was from the floor to the greater trochanter $[15,18,19]$, the length of Cane 2 was from the floor to the distal wrist crease [22], and Cane 3 was a shorter cane that resulted in approximately $20^{\circ}$ of elbow flexion when held in a neutral, upright position; the final cane category was No Cane. Step heights were 0 (ground level), 18, 27, and $33 \mathrm{~cm}$. All tests consisted of descending a single step $45 \mathrm{~cm}$ deep, $90 \mathrm{~cm}$ wide, and of varying height. Dependent variables were the center of pressure (CoP), measured by a low-pass filter force plate, and electromyography (EMG) signals (NeXus-10, 1,024 $\mathrm{Hz}$, MindMedia, Netherlands). EMG patches were attached over the biceps brachii of the arm that usually held the cane and both gastrocnemius muscles.

\section{Procedure}

The total experiment time was approximately $40 \mathrm{mi}-$ nutes (Figure 1). Participants were asked to sit down and rest for 15 minutes while the apparatus was set up. After the 15 minute rest, the participants completed tests 1 through 4. In each test, participants stood on the step and stepped down onto the force plate when asked to by the researcher. A handrail was available during each test for the participants to use at their discretion. After stepping down, the participants stood on the force plate for at least 10 seconds and then repeated the test. Each test combination of cane length and step height was repeated twice. All participants completed four randomly selected tests of different step heights and cane lengths each day, and finished all 16 combinations within four sessions.

\section{Data analysis}

The EMG signals were transformed in MATLAB to root mean square (RMS) values and then divided by the 
Table 1 Participant data

\begin{tabular}{llllllllll}
\hline Participant & Gender & Use cane usually & Osteoarthritis & Age & Height $(\mathbf{c m})$ & Weight $\mathbf{( k g )}$ & Cane $\mathbf{1}(\mathbf{c m})$ & Cane 2 (cm) & Cane 3 (cm) \\
\hline 1 & Female & Yes & No & 87 & 150 & 42.5 & 76 & 73 & 70.5 \\
2 & Female & Yes & Yes & 80 & 150 & 45 & 80 & 76 & 70.5 \\
3 & Female & No & No & 86 & 148 & 60 & 78 & 73 & 70.5 \\
4 & Female & Yes & Yes & 93 & 168 & 58 & 85 & 74 & 76 \\
5 & Male & Yes & No & 85 & 166 & 67 & 86 & 78 & 76 \\
6 & Male & Yes & No & 83 & 167 & 68 & 90 & 85 & 76 \\
7 & Male & Yes & Yes & 65 & 168 & 86 & 90 & 85 & 76 \\
8 & Male & No & No & 81 & 168 & 60 & 88 & 85 & 76 \\
9 & Male & No & No & 85 & 163 & 58 & 83 & 80 & 76 \\
Average & Female $=4$ & Yes $=6$ & Yes $=3$ & 82.78 & 160.89 & 60.50 & 84.00 & 78.78 & 74.17 \\
Standard Deviation & Male $=5$ & No $=3$ & No $=6$ & 7.66 & 8.82 & 12.87 & 5.12 & 5.19 & 2.75 \\
\hline
\end{tabular}

MAX RMS, which was the maximum activity in the measured part of the muscle, and expressed as RMS(\%). The CoP signals were expressed in terms of Stabilometric Parameters, which are described in Table 2. We collected EMG signals from the loading response period, which began when the participant's feet first contacted the force plate and ended one second later. The first foot contact was defined as when the first foot landed on the force plate (which foot was first depended on the participant's preference; Figure 2) and the second foot contact was defined as when the second foot contacted the force plate. The CoP signal was recorded from when the first foot touched the force plate and ended when the person was standing squarely with both feet on the force plate. The RMS(\%) values are shown as means \pm standard deviation. Statistical analyses were performed using Minitab, version 16. Two-way ANOVA was used to examine whether step height or cane length affected muscle load and balance in the study participants. Differences were considered significant if $P<0.05$.

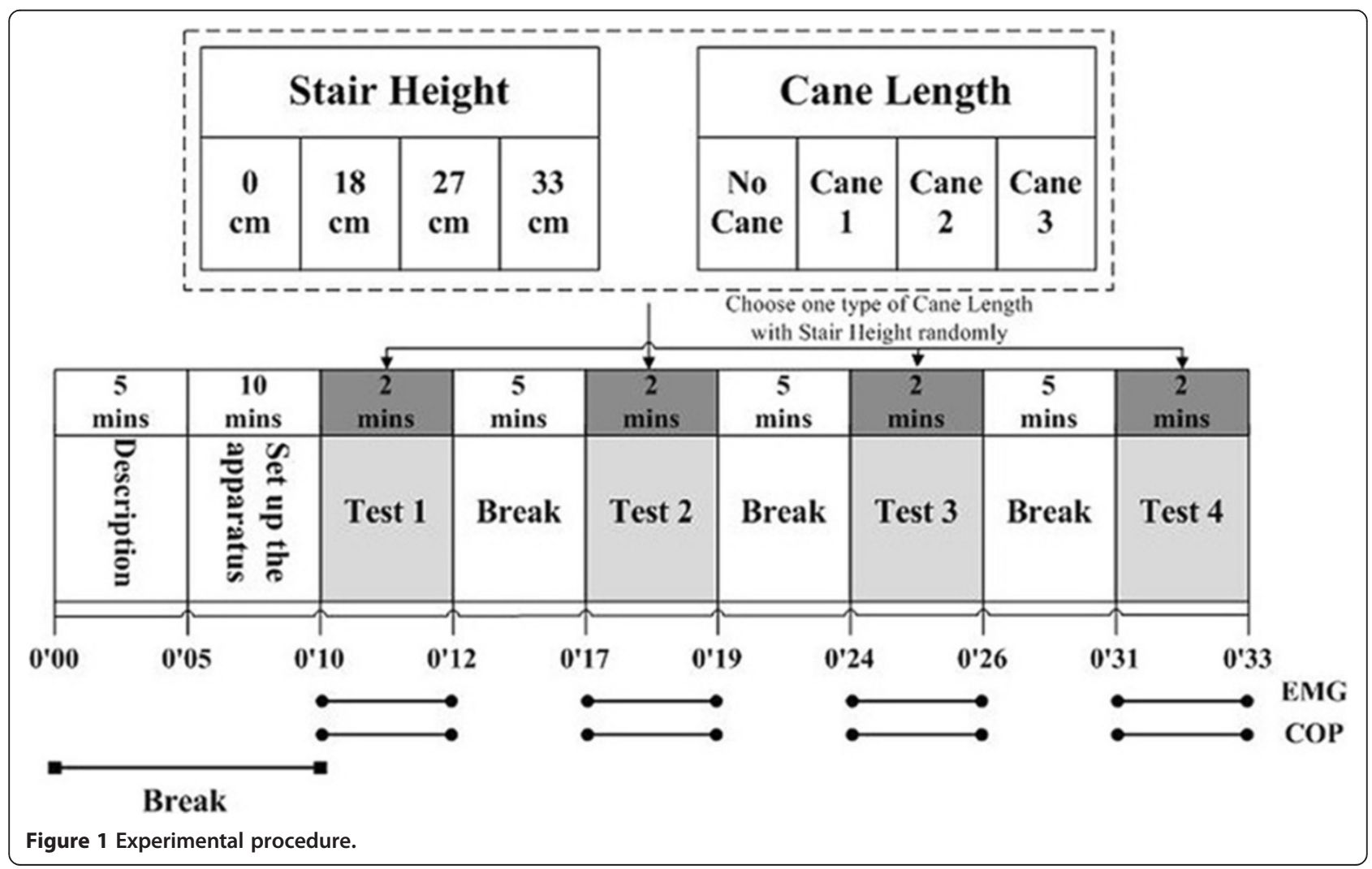


Table 2 Description of stabilometric parameters

\begin{tabular}{|c|c|}
\hline $\begin{array}{l}\text { Stabilometric } \\
\text { parameters }\end{array}$ & Description \\
\hline MDIST & The mean of the resultant distance time series and represents the average distance from the mean center of pressure (CoP) \\
\hline MDIST_AP & The mean absolute value of the antero-posterior (AP) time series and represents the average AP distance from the mean CoP \\
\hline MDIST_ML & The mean absolute value of the medio-lateral $(\mathrm{ML})$ time series and represents the average $\mathrm{ML}$ distance from the mean CoP \\
\hline RDIST & The root mean square value of the resultant distance time series \\
\hline RDIST_AP & The standard deviation of the AP time series \\
\hline RDIST_ML & The standard deviation of the ML time series \\
\hline TOTEX & The total length of the CoP path and is approximated by the sum of the distances between consecutive points in the CoP path \\
\hline TOTEX_AP & $\begin{array}{l}\text { The total length of the CoP path in AP direction and is approximated by the sum of the distances between consecutive } \\
\text { points in the time series }\end{array}$ \\
\hline TOTEX_ML & $\begin{array}{l}\text { The total length of the CoP path in the ML direction and is approximated by the sum of the distances between consecutive } \\
\text { points in the ML time series }\end{array}$ \\
\hline MVELO & The average velocity of the CoP \\
\hline MVELO_AP & The average velocity of the CoP in the AP direction \\
\hline MVELO_ML & The average velocity of the CoP in the ML direction \\
\hline 95\%CC AREA & The area of the circle with a radios equal to the one-side $95 \%$ confidence limit of the resultant distance time series \\
\hline
\end{tabular}

\section{Results}

\section{Descriptive statistics}

The mean cane lengths used by the study participants were $84.00 \pm 5.12 \mathrm{~cm}$ (Cane 1), $78.78 \pm 5.19 \mathrm{~cm}$ (Cane 2), and $74.17 \pm 2.75 \mathrm{~cm}$ (Cane 3); these results are shown in Table 1 .

\section{EMG Results}

Representative EMG signals from one older individual showing the load on the muscles of the arm, on the leg at

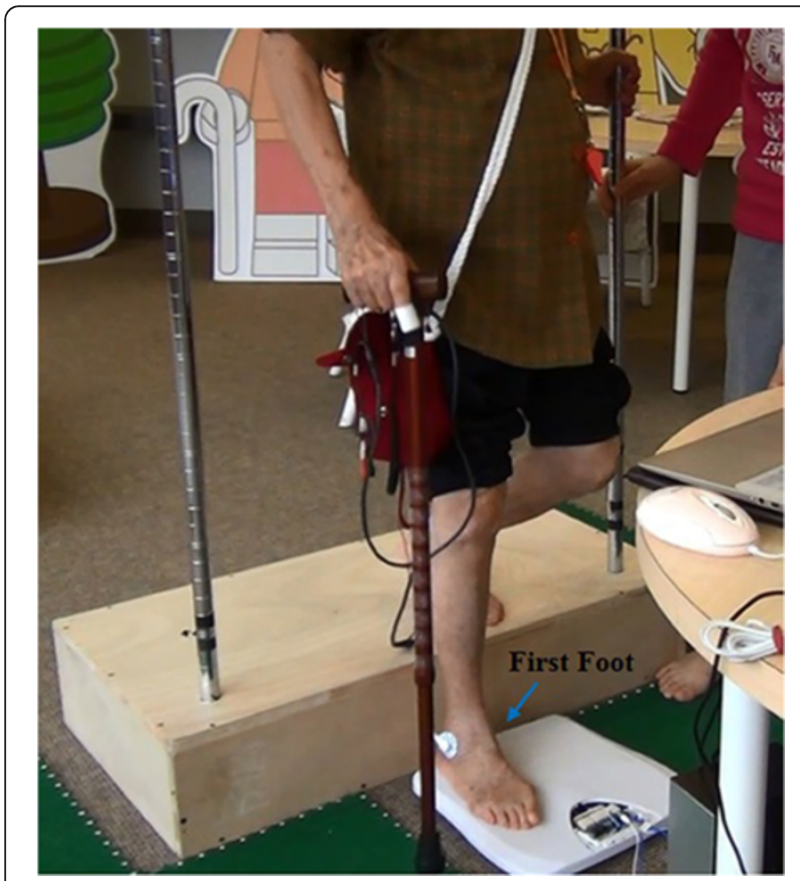

Figure 2 An illustration of the first foot. the first foot contact, and on the leg at the second foot contact are shown in Figures 3, 4, and 5. Statistical analysis of data from all participants revealed that higher steps were associated with greater load on the arm (Table 3), and there were significant differences in RMS between the $0 \mathrm{~cm}(0.57 \pm 0.34)$ and both the $27 \mathrm{~cm}$ $(1.01 \pm 0.89)$ and the $33 \mathrm{~cm}$ steps $(1.17 \pm 1.18$; Figure 6; $P<0.05)$. EMG data from the gastrocnemius muscle at the first foot contact revealed similar results, with the load on the gastrocnemius muscle when stepping down from $33 \mathrm{~cm}(0.89 \pm 0.90)$ being significantly greater than when stepping down from both $0 \mathrm{~cm}(0.53 \pm 0.70)$ and $18 \mathrm{~cm}(0.48 \pm 0.51$; Figure 7; $P<0.05)$; however, the load after stepping down $0 \mathrm{~cm}$ tended to be greater than after stepping down $18 \mathrm{~cm}$, although this difference was non-significant. The RMS value for the second step was not significantly affected by step height. Cane length did not significantly affect any RMS values.

Figure 8 shows the original CoP data plotted for one older individual in each of the different experimental combinations (different step heights and cane lengths). Statistical analysis revealed that the CoP Stabilometric Parameters MDIST, MDIST_AP, TOTEX, TOTEX_AP, MVELO, and MVELO_AP were significantly affected by step height (Table 4). Figures 9 and 10 show the results for the MDIST and MDIST_AP parameters, which indicate that participants swayed more when stepping down $0 \mathrm{~cm}$ than when stepping down $27 \mathrm{~cm}(P<0.05)$; the results were similar for the other parameters. CoP values were not significantly affected by cane length; however, we did observe that Cane 3 resulted in slightly more sway than the other cane lengths as measured by MDIST_ML $(P=0.076$; Figure 11). 


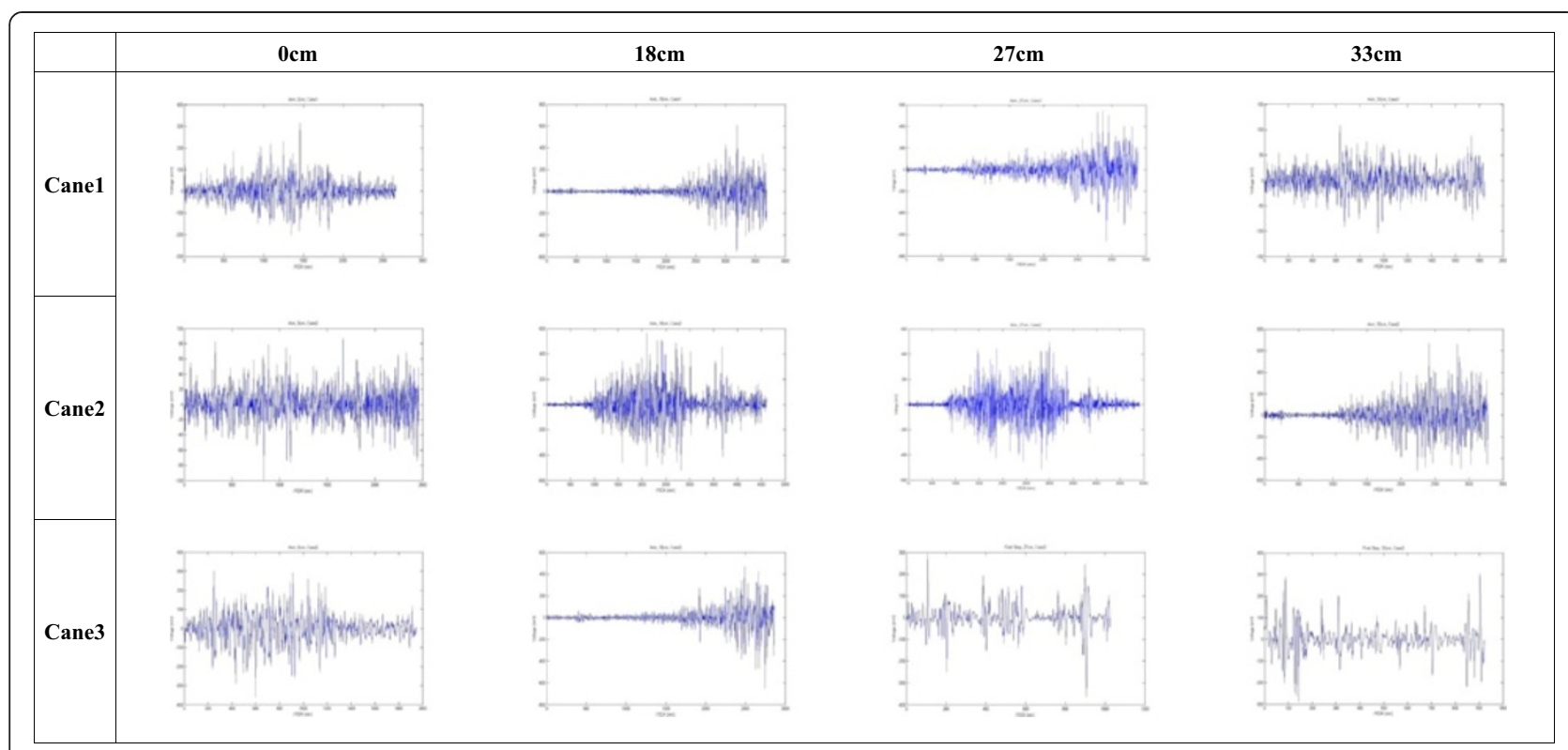

Figure 3 Arm electromyography signal during each experimental scenario. $x$-axis represents time/1,024 (sec) and $y$-axis represents voltage $(\mathrm{mV})$, which indicates muscle force. One participant was taken as an example.

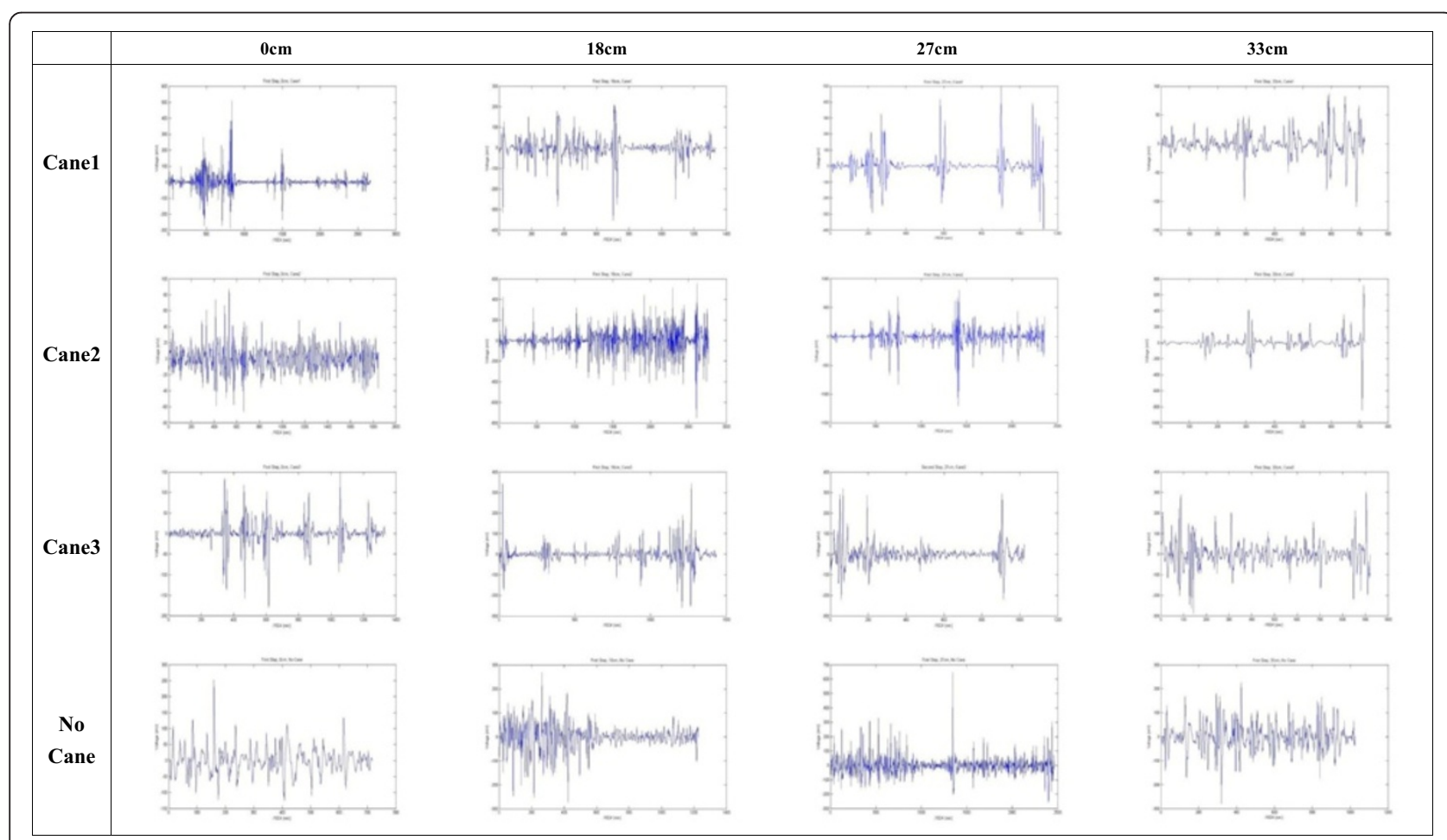

Figure 4 Leg electromyography signal at the first foot contact during each different experimental scenario. $x$-axis represents time/1,024 $(\mathrm{sec})$ and $\mathrm{y}$-axis represents voltage $(\mathrm{mV})$, which indicates muscle force. One participant was taken as an example. 


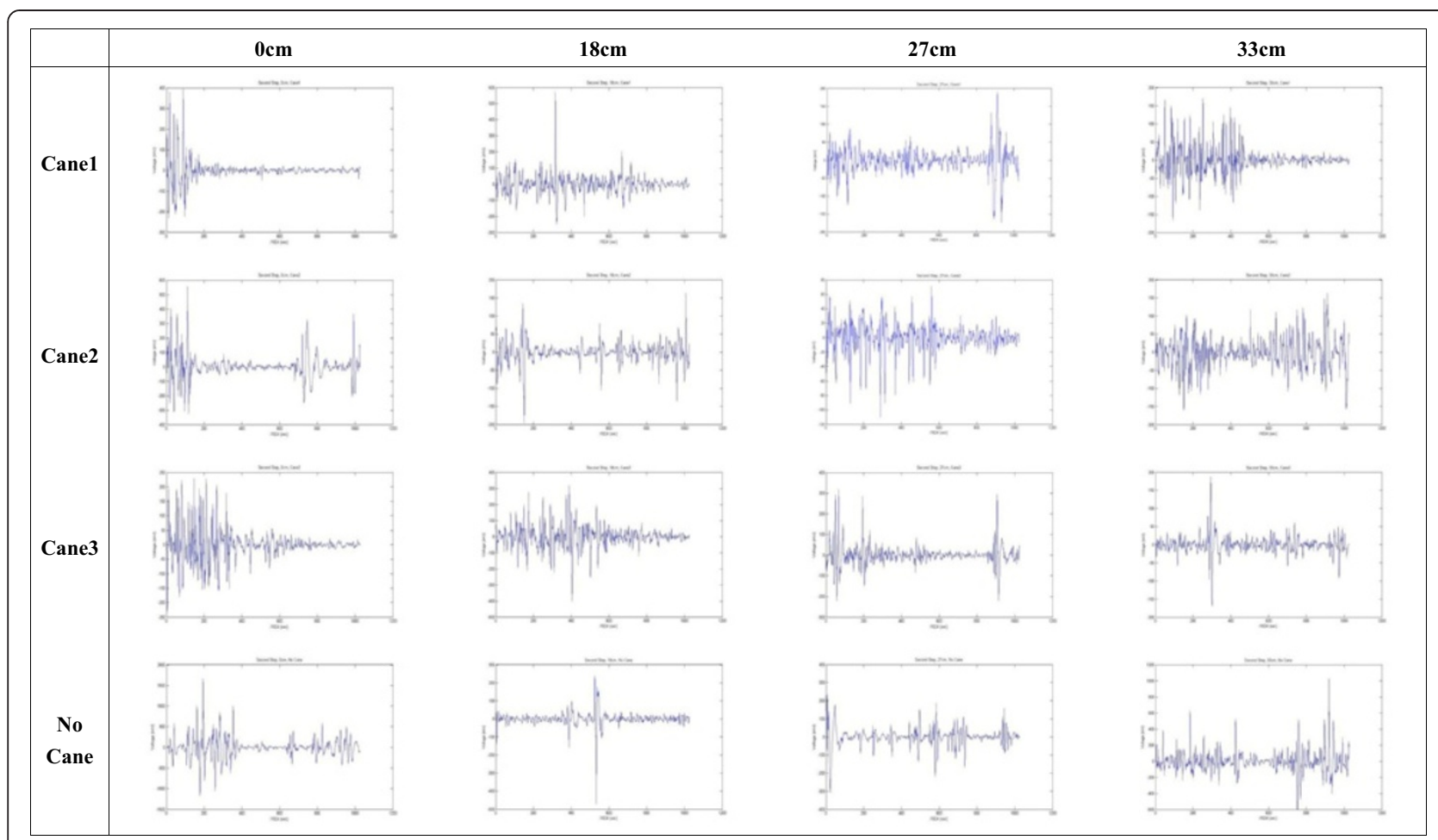

Figure 5 Leg electromyography signal at the second foot contact during each different experimental scenario. $x$-axis represents time/ $1,024(\mathrm{sec})$ and $\mathrm{y}$-axis represents voltage $(\mathrm{mV})$, which can be transferred to muscle force.

\section{Discussion}

The EMG signal is a recording of physiological variations in muscle fiber membranes. As muscle contraction increases, the EMG signal amplitude increases [23]. CoP is the location of the vertical reaction vector when a subject stands on a plane [24]. The CoP reflects the orientation of the body, as well as its movement to maintain its center of gravity. A higher CoP indicates that the body might be unbalanced.

Table 3 Root mean square (RMS)(\%) of the electromyography signal

Arm (RMS) First foot (RMS) Second foot (RMS)

\section{Step height $(\mathrm{cm})$}

0

18

27

33

Cane length

Cane 1

Cane 2

$0.57^{*} \pm 0.34$

$0.53^{*} \pm 0.70$

$0.63 \pm 0.80$

$0.89 \pm 0.83$

$0.48 \pm 0.51$

$0.45 \pm 0.58$

$1.01 * \pm 0.89$

$0.70^{*} \pm 0.88$

$0.41 \pm 0.34$

$1.17^{*} \pm 1.18$

$0.89^{*} \pm 0.89$

$0.46 \pm 0.57$

Cane 3

$0.92 \pm 0.95$

$0.70 \pm 0.87$

$0.47 \pm 0.44$

$0.75 \pm 0.68$

$0.71 \pm 0.93$

$0.49 \pm 0.67$

No cane

$1.02 \pm 0.94$

$0.52 \pm 0.55$

$0.51 \pm 0.72$

$0.64 \pm 0.69$

$0.50 \pm 0.57$

\section{Stair environment}

\section{EMG}

Step height is an important factor that affects both the hip and knee flexors [25]. Müller et al. [26] measured the force on adult joints when ascending or descending three different stair inclination angles, and found that the force on joints increased as the stair inclination angle increased. The difference in force between the minimum and maximum inclinations tested was $14.8 \%$. The results of the current study were similar; the RMS(\%) value for the arm showed that participants experienced greater muscle loads when stepping down from a greater height. The same was true of the load on the gastrocnemius muscle at the first foot contact, except for the tendency for less muscle load after stepping down from an $18 \mathrm{~cm}$ high step than during level walking $(0 \mathrm{~cm})$.

Individuals took multiple steps as a pre-planned strategy in various situations [27], often causing the steps taken after the first step to appear unstable [28]. This study showed that the first step was the key to maintaining balance. Thus, the first step might have been more significantly affected by step height than the second step, as the first step may have a more important role in maintaining stability. Based on the results of the present study and past research, older individuals who selected suitable strategies maintained better balance in different environments. 


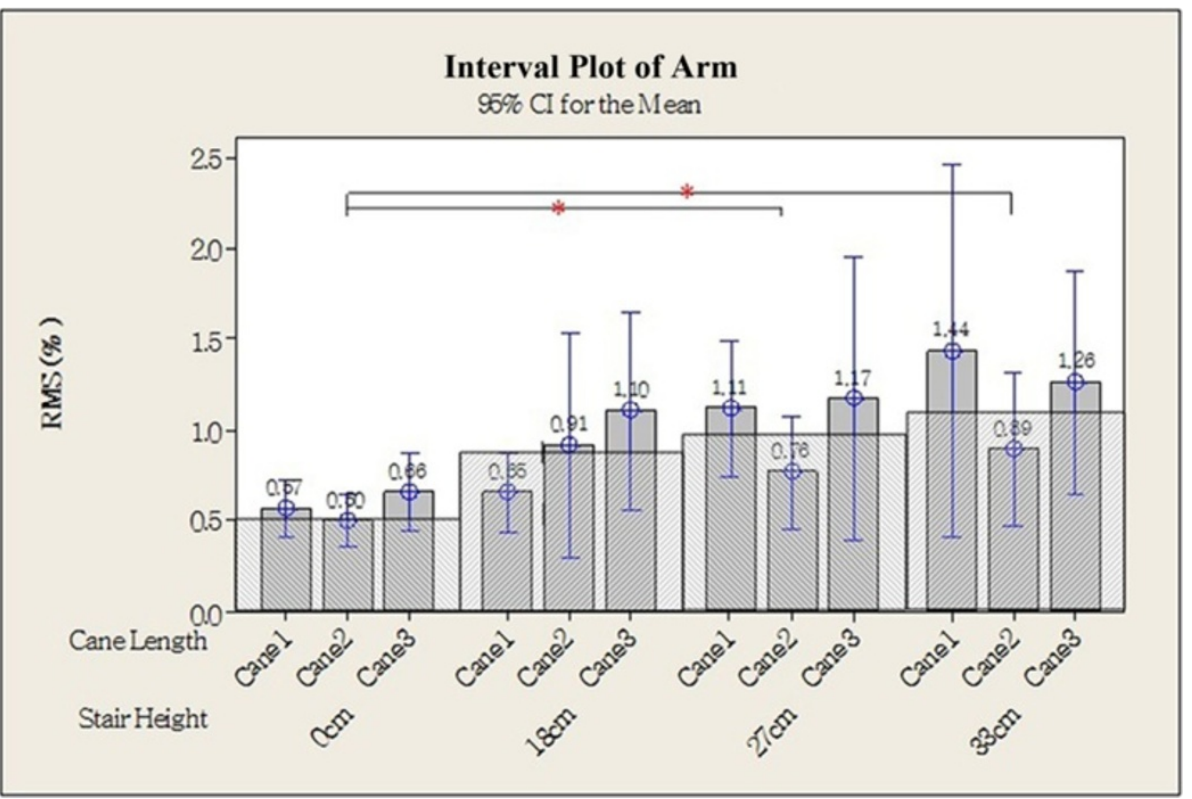

Figure 6 Root mean square of the arm. ${ }^{*} P<0.05$, two-tailed.

The ability of a cane to assist with maintaining stability can be observed through the relationship between the EMG signals from the gastrocnemius and the biceps brachii at the time of the first foot contact. Participants used greater arm force to reduce the muscle load on their leg. Joyce and Kirby have previously reported that the use of a cane can reduce pressure on the lower limbs [15]. If older people properly apply force to a cane, it may reduce the force on their feet and legs.
This movement strategy may be suitable for older individuals with leg weakness.

\section{CoP}

The CoP results showed that the sway amplitude during level walking $(0 \mathrm{~cm})$ was larger than when descending a $27 \mathrm{~cm}$ high step, especially in the AP direction. This corresponds with past research, which showed that the ground reaction forces were smaller when ascending and

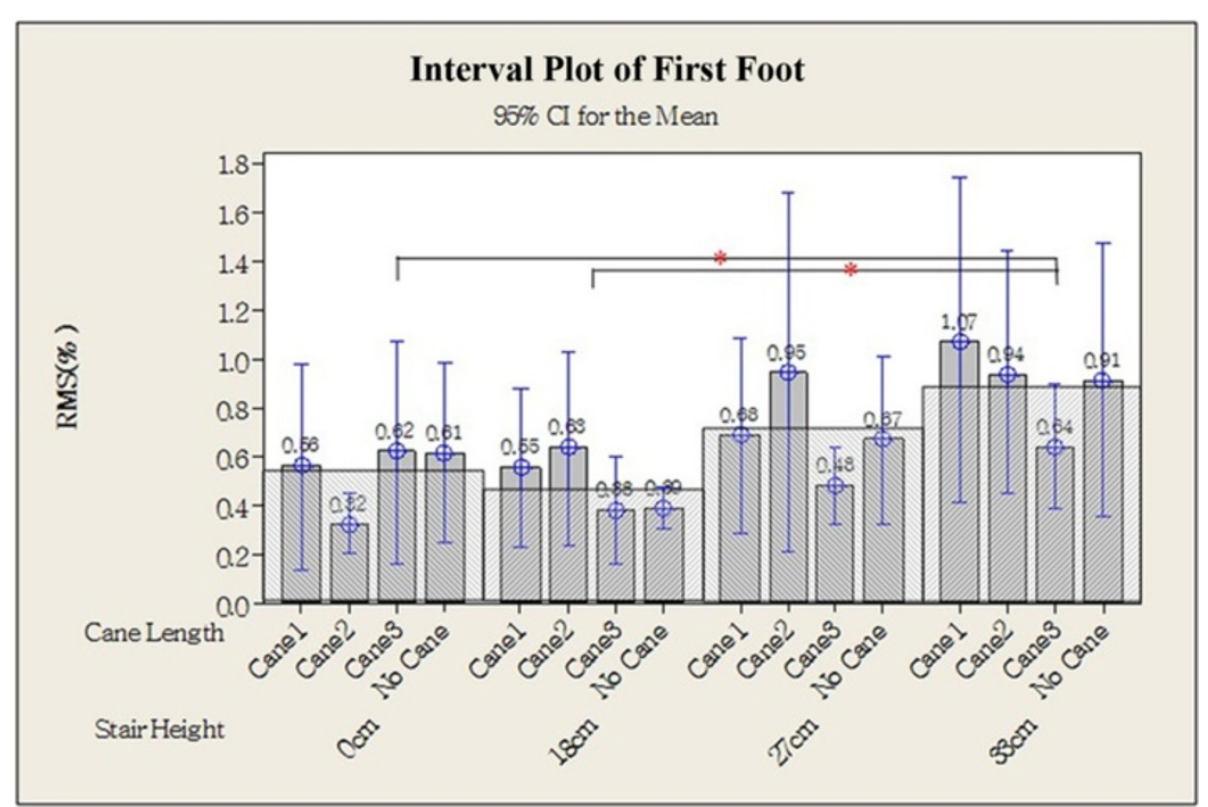

Figure 7 Root mean square of the gastrocnemius muscle at the first foot contact. ${ }^{*} P<0.05$, two-tailed. 


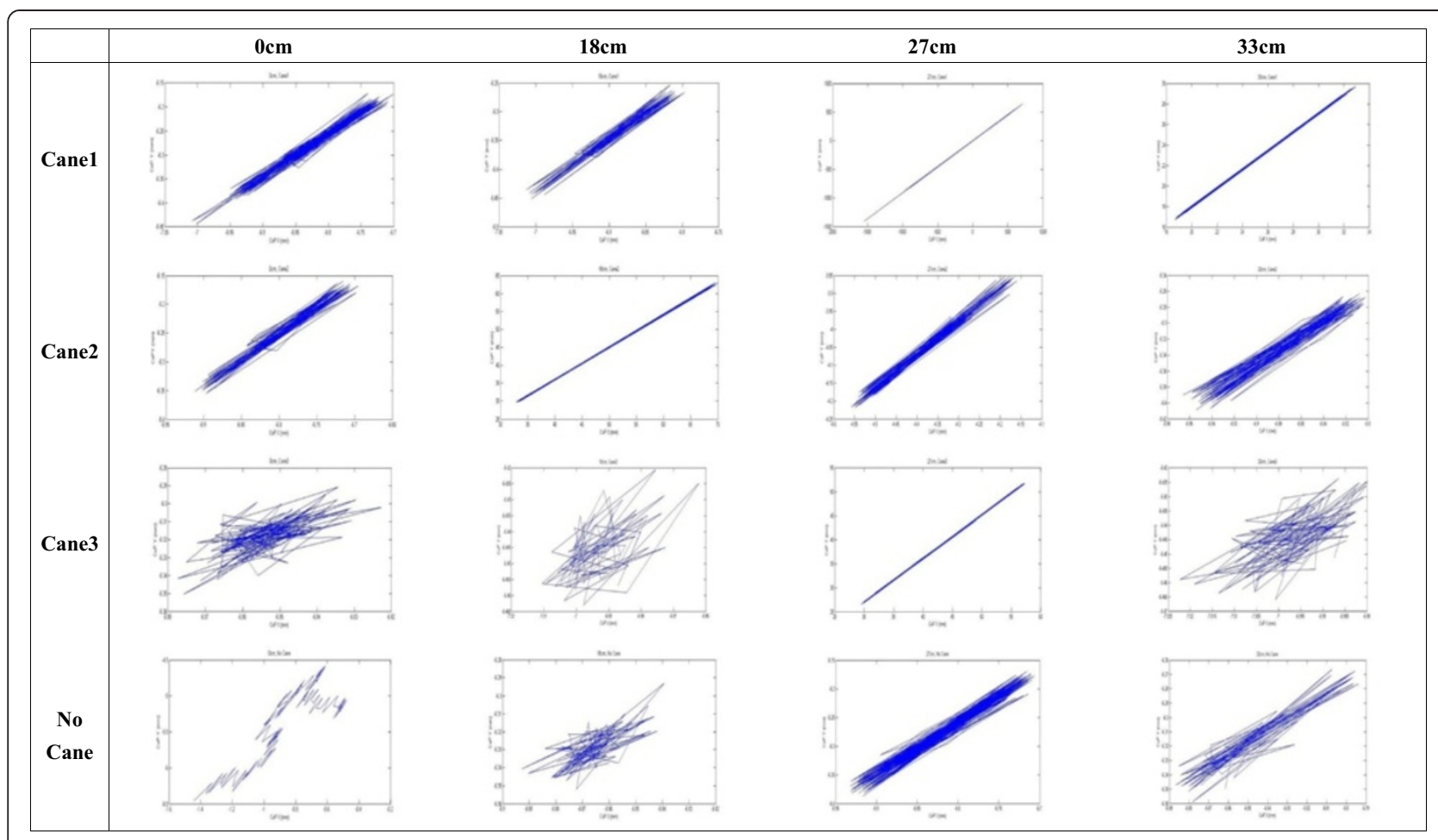

Figure 8 Center of pressure (CoP) signal during each experimental scenario. $x$-axis represents the ML direction (mm) and $y$-axis represents the AP direction $(\mathrm{mm})$. One participant was taken as an example.

descending stairs than during level walking, and that step height had a significantly greater effect in the AP than in the ML direction [26]. Lu et al. [29] studied 10 older stroke patients who performed level walking without a cane, and found that sway was more evident in the AP direction than in the ML direction. Thus, it can be inferred that AP sway controls body stability more than ML sway.

\section{Relationship between EMG and CoP}

For the synoptic composites in this study, the EMG and $\mathrm{CoP}$ results were similar to those reported previously. First, as stair height increased, muscle load increased. Second, the body can gain greater balance with the application of greater force. In particular, the participants exerted greater force to improve balance as step height increased, maintaining relatively better balance than when stepping down from lower step heights. Observation of the participants during level walking and $18 \mathrm{~cm}$ step height conditions revealed that when the participants used slightly more arm force they were able to reduce the muscular load on both legs, as well as to achieve a state of equilibrium superior to that achieved during level walking. Thus, conscious application of arm muscle force could reduce loads on the limb muscles and improve balance. In addition, the participants paid more attention during the different step situations than during level walking, and as a result their balance improved. In short, we suspect that setting suitable obstacles into their daily environment might make older people pay more attention to walking and, therefore, improve their stability. However, a comparison of 27 and $33 \mathrm{~cm}$ step heights showed that sway increased as step height increased, despite increases in the forces generated by the arm and both legs. This suggests that descending stairs that are too steep is laborious for older individuals.

\section{Cane length}

\section{EMG}

Our results indicate that cane length does not affect the force exerted by the arm and both legs when descending a step. When the participants held a cane with their elbow flexed at $20^{\circ}$ to $30^{\circ}$, the cane helped offset their body weight. Although there were three different cane lengths, all were within the standard recommendations for cane length, which might explain why cane length had no significant effect in this study. In a previous study, researchers measured heart rate in osteoarthritis patients during walking with different cane lengths and found that there were no significant differences if the cane length was within the suggested measurements [20]. Additionally, the provision of a handrail offered extra assistance, allowing subjects to exert more force than usual on the arm not holding the cane. 
Table 4 Stabilometric parameter center of pressure values

\begin{tabular}{|c|c|c|c|c|c|c|c|c|}
\hline & & MDIST (mm) & $\begin{array}{l}\text { MDIST_AP } \\
(\mathrm{mm})\end{array}$ & $\begin{array}{l}\text { MDIST_ML } \\
(\mathrm{mm})\end{array}$ & RDIST (mm) & RDIST_AP (mm) & $\begin{array}{l}\text { RDIST_ML } \\
(\mathrm{mm})\end{array}$ & \\
\hline \multicolumn{9}{|c|}{ Stair height $(\mathrm{cm})$} \\
\hline & 0 & $69.86^{*}$ & $58.73^{*}$ & 16.67 & 157.77 & 148.38 & 19.24 & \\
\hline & 18 & 49.21 & 37.3 & 16.75 & 118.2 & 106.78 & 19.34 & \\
\hline & 27 & $31.21^{*}$ & $19.96^{*}$ & 15.52 & 56.7 & 46.71 & 17.92 & \\
\hline & 33 & 38.1 & 25.99 & 16.42 & 81.29 & 70.01 & 18.96 & \\
\hline \multicolumn{9}{|c|}{ Cane length } \\
\hline & Cane 1 & 52.18 & 40.89 & 16.07 & 115.68 & 105.59 & 18.55 & \\
\hline & Cane 2 & 40.33 & 30.85 & 14.45 & 89.48 & 81.63 & 16.69 & \\
\hline & Cane 3 & 39.92 & 23.96 & 20.35 & 78.71 & 62.92 & 23.49 & \\
\hline & No cane & 55.99 & 46.37 & 14.49 & 130.16 & 121.91 & 16.73 & \\
\hline & $\begin{array}{l}\text { TOTEX } \\
(\mathrm{mm})\end{array}$ & $\begin{array}{l}\text { TOTEX_AP } \\
(\mathrm{mm})\end{array}$ & $\begin{array}{l}\text { TOTEX_ML } \\
(\mathrm{mm})\end{array}$ & $\begin{array}{l}\text { MVELO } \\
(\mathrm{mm} / \mathrm{s})\end{array}$ & $\begin{array}{l}\text { MVELO_AP } \\
(\mathrm{mm} / \mathrm{s})\end{array}$ & $\begin{array}{l}\text { MVELO_ML } \\
(\mathrm{mm} / \mathrm{s})\end{array}$ & $\begin{array}{l}\text { AREA_CC } \\
(\mathrm{mm} / \mathrm{s})\end{array}$ & $\begin{array}{l}\text { AREA_SW } \\
\left(\mathrm{mm}^{2} / \mathrm{s}\right)\end{array}$ \\
\hline \multicolumn{9}{|c|}{ Stair height $(\mathrm{cm})$} \\
\hline 0 & $3,394.67^{*}$ & $3,356.67^{*}$ & 65.68 & $7,000.23^{*}$ & $6,594.67^{*}$ & 97.79 & 942,720 & $33,164.3$ \\
\hline 18 & $1,782.83$ & $1,739.2$ & 66.02 & $3,680.02$ & $3,625.57$ & 97.66 & 675,821 & $22,019.5$ \\
\hline 27 & $892.97^{*}$ & $853.1^{*}$ & 61.08 & $1,912.16^{*}$ & $1,855.54^{*}$ & 97.69 & 161,771 & $8,700.69$ \\
\hline 33 & $1,412.08$ & $1,368.99$ & 64.68 & $3,017.75$ & $2,958.12$ & 97.88 & 548,671 & $10,991.6$ \\
\hline \multicolumn{9}{|c|}{ Cane length } \\
\hline Cane 1 & $1,882.77$ & $1,844.39$ & 63.28 & $4,706.18$ & $4,655.36$ & 97.59 & 593,516 & $18,350.6$ \\
\hline Cane 2 & $1,559.83$ & $1,526.06$ & 56.83 & $3,117.07$ & $3,064.48$ & 97.73 & 372,360 & $14,669.7$ \\
\hline Cane 3 & $1,546.71$ & $1,489.46$ & 80.4 & $2,467.78$ & $2,408.74$ & 97.99 & 363,491 & $12,425.7$ \\
\hline $\begin{array}{l}\text { No } \\
\text { cane }\end{array}$ & $2,492.99$ & $2,451.8$ & 56.97 & $5,284.63$ & $5,231.35$ & 97.71 & 971,282 & $29,395.9$ \\
\hline
\end{tabular}

${ }^{*} P<0.05$, two-tailed.

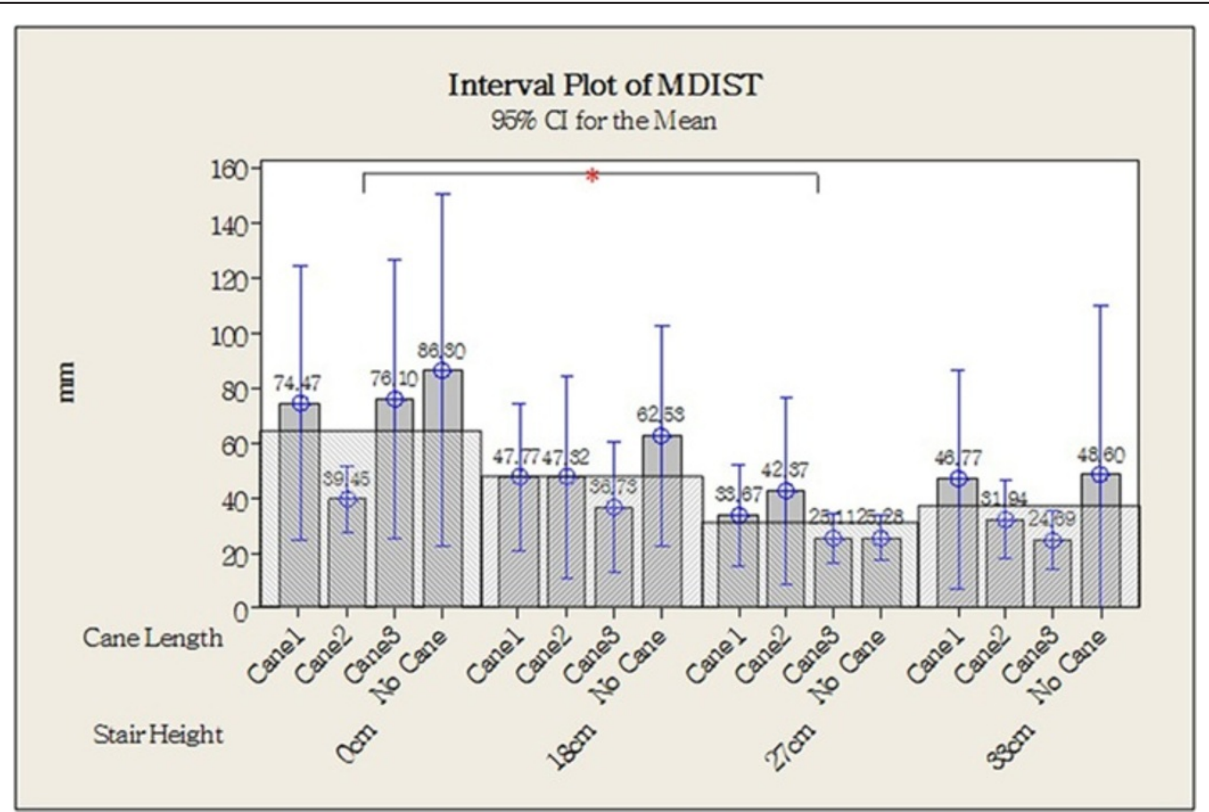

Figure 9 Center of pressure (COP) value of mean distance (MDIST; with step height as the main factor). ${ }^{*} P<0.05$, two-tailed. 


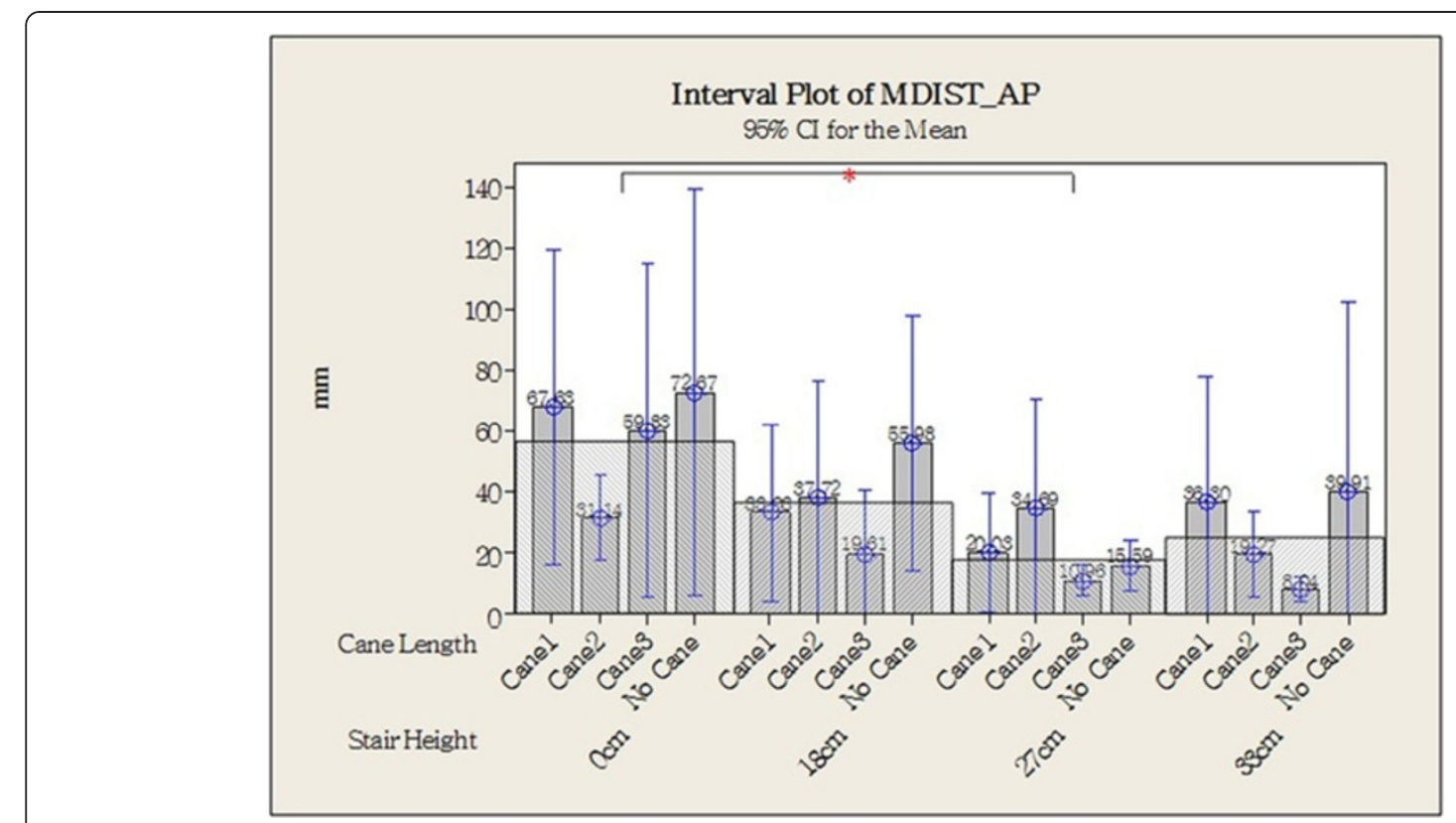

Figure 10 Center of pressure (COP) value of antero-posterior mean distance (MDIST_AP; with stair height as the main factor). ${ }^{*} P<0.05$, two-tailed.

\section{CoP}

Cane length did not have a large effect on balance, having a small effect only on ML parameters such as MDST_ML $(P=0.076)$, RDST_ML $(P=0.076)$, and TOTEX_ML $(P=$ 0.076). However, Lu et al. [29] found that stroke patients swayed less when using Cane 2 than when using Cane 1. The selection of subjects, or the variation between the older participants in that study and this one, may have caused this difference in results.
Cane length in our study tended to affect the participants' stability in the ML direction. Our results showed that participants swayed more when using Cane 3 than the other cane lengths. It can be inferred that using a shorter cane may offer similar stability to longer canes in the AP direction, but does not provide enough $\mathrm{ML}$ stability.

As previously mentioned, factors such as the installation of handrails, standard cane lengths, and other variables

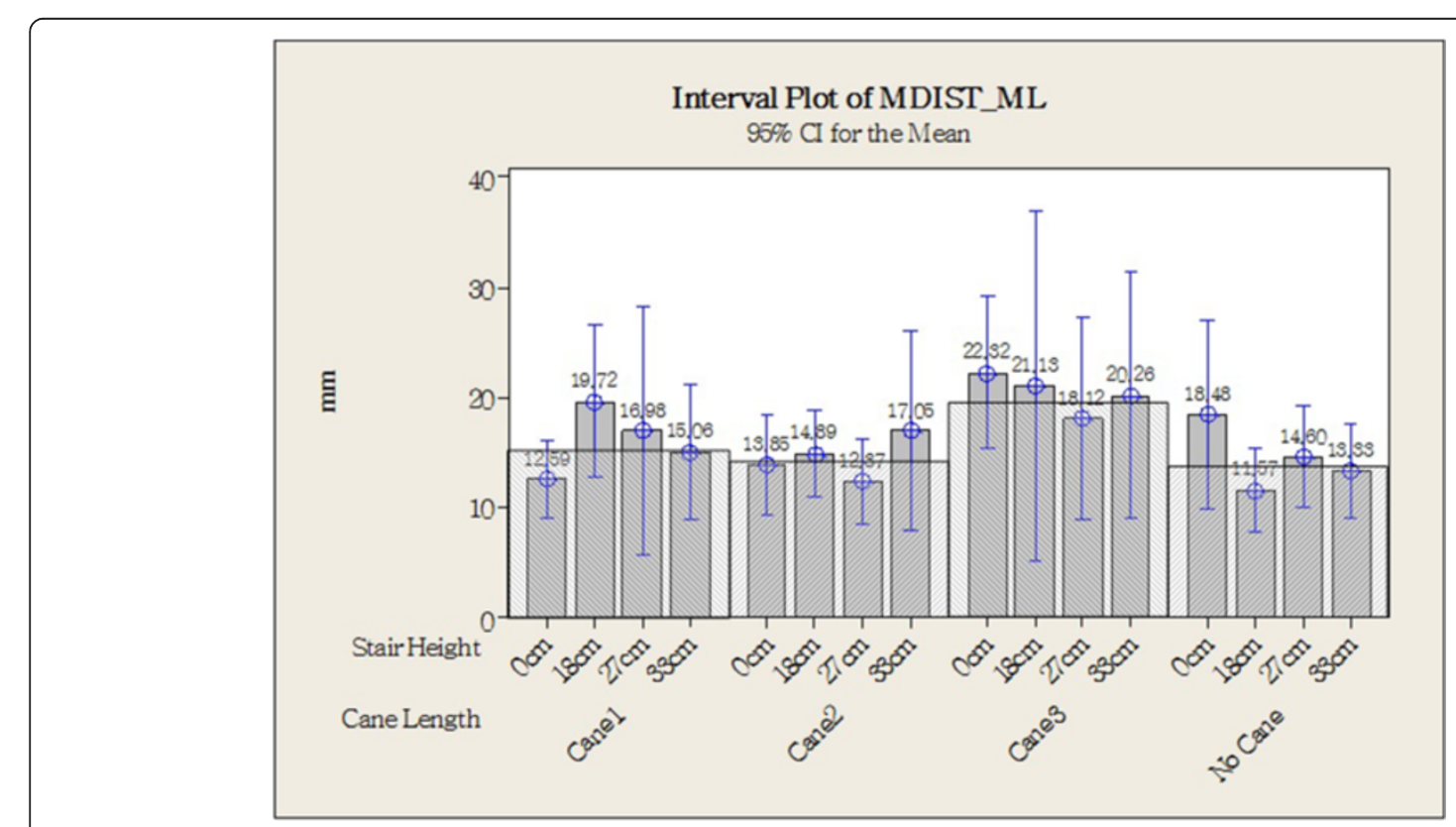

Figure 11 Center of pressure (COP) value of medio-lateral mean distance (MDIST_ML; with cane length as the main factor). ${ }^{*} P<0.05$, two-tailed. 
might have affected the participants' equilibrium. These factors are as follows: i) Participants did not use their original canes: the canes used in this experiment were supplied by the researchers. They may have felt different from the participants' usual canes, and therefore caused changes in movement while stepping down. ii) Exercise habits: the participants differed in their normal exercise habits. Therefore, their ability to exert force differed, which may have caused them to use different strategies to walk down stairs. iii) Physiological condition: any unknown disease could have affected the participants' performance during the experiment; however, individual differences between subjects cannot be avoided. iv) Adaptability: humans are able to adapt well to changes in their environment. Participants might have been affected by the variables in the beginning of the experiment, but they may have gradually acclimated to them and become less affected by step height or cane length.

\section{Conclusions}

The results of this study demonstrate the physiological effects of different cane lengths and step heights on older people. The main results of the study indicated that cane length did not greatly affect the load on the arm or legs when descending a step. If the cane length is within the normally recommended limits, it helps the user gain stability during movement. Further, step height has a greater effect on stability than cane length. Thus, greater step height causes older people to adopt different strategies to improve their stability. When stepping off the 0 and 18 $\mathrm{cm}$ steps, increased load on the arm and lower muscle load on the legs resulted in greater stability. However, when stepping down from 27 and $33 \mathrm{~cm}$, body sway was still greater than seen with the lower steps, even though muscle load was also greater.

We hope that this study will provide useful information for other researchers who are also interested in the effects of the stair environment on balance and mobility in older people.

\section{Abbreviations \\ AP: Antero-posterior; CoP: Center of pressure; EMG: Electromyography; MDIST: Mean distance; MDIST_AP: Antero-posterior mean distance; MDIST_ML: Medio-lateral mean distance; ML: Medio-lateral; MVELO: Mean velocity; MVELO_AP: Antero-posterior mean velocity; RMS: Root mean square; TOTEX: Total excursions; TOTEX_AP: Antero-posterior total excursions.}

\section{Competing interests}

The authors declare that they have no competing interests.

\section{Author contributions}

ZY collected experimental data, performed statistical analysis and wrote the manuscript. C participated in the design of these study, revised the manuscript and supervised the study. All authors read and approved the final manuscript.

Received: 28 May 2014 Accepted: 27 November 2014 Published: 21 December 2014

\section{References}

1. Lee CF, Kuo CC: A Pilot Study of Ergonomic Design for Elderly Taiwanese People. Seoul, Korea: Proceedings of the 5th Asian Design ConferenceInternational Symposium on Design Science; 2001.

2. Okada A: Ergonomics approach in universal design. Special Issue JSSD 1997, 4(4):40-45.

3. Lexell J, Taylor CC, Sjostrom M: What is the cause of the ageing atrophy? Total number, size, and proportion of different fiber types studied in whole vastus lateralis muscle from 15 to 83-year-old men. J Neurol Sci 1988, 84(2-3):275-294.

4. Young A, Stokes M, Crowe M: The size and strength of the quadriceps muscles of old and young men. Clin Physio/ 1985, 5(2):145-154.

5. Waters DL, Baumgartner RN, Garry PJ: Sarcopenia: current perspectives. J Nutr Health Aging 2000, 4(3):133-139.

6. Nevitt MC, Cummings SR, Kidd S, Black D: Risk factors for recurrent nonsyncopal falls. A prospective study. J Am Med Assoc 1989, 261(18):2663-2668.

7. Robbins AS, Rubenstein LZ, Josephson KR, Schulman BL, Osterweil D, Fine G: Predictors of falls among elderly people: results of two population based studies. Arch Intern Med 1989, 149(7):1628-1633.

8. Sieri T, Beretta G: Fall risk assessment in very old males and females living in nursing homes. Disabil Rehabil 2004, 26(12):718-723.

9. Daley MJ, Spinks WL: Exercise, mobility and aging. Sports Med 2000 29(1):1-12.

10. Colling J, Park D: Home, safe home. J Gerontol Nurs 1983, 9(3):175-192.

11. McVey LJ, Studenski SA: Falls in elderly. Adv Clin Rehabil 1988, 2:108-131.

12. Blake AJ, Morgan K, Bendall MJ, Dallosso H, Ebrahim SB, Arie TH, Fentem PH, Bassey EJ: Falls by elderly people at home: prevalence and associated factors. J Aging Phys Act 1988, 17(6):365-372.

13. Graafmans WC, Ooms ME, Hofstee HMA, Bezemer PD, Bouter LM, Lips P: Falls in the elderly: a prospective study of risk factors and risk profiles. Am J Epidemiol 1996, 143(11):1129-1136.

14. Tinetti ME, Speechley M, Ginter SF: Risk factors for falls among elderly persons living in the community. N Eng J Med 1988, 319(26):1701-1707.

15. Joyce BM, Kirby RL: Canes, crutches and walkers. Am Fam Physician 1991, 43(2):535-542.

16. Mully GP: Everyday aids and appliances: walking sticks. Br Med J 1988, 296(6620):475-476.

17. Jebsen RH: Use and abuse of ambulation aids. J Am Med Assoc 1967, 199(1):5-10.

18. Sainsbury R, Mulley GP: Walking sticks used by the elderly. Br Med J 1982, 284(6331):1751.

19. Dean $E$, Ross M: Relationships among cane fitting function and falls. Phys Ther 1993, 73(8):494-500.

20. Jones A, Monteiro Alves AC, de Oliveira LM, Saad M, Natour J: Energy expenditure during cane-assisted gait in patients with knee osteoarthritis. Clinics 2008, 63(2):197-200.

21. Kim K, Cha YJ: Cane length influence on plantar pressure distribution of adult Hemiplegia patients. J Phys Ther Sci 2011, 23(3):451-454.

22. DeLisa JA, Currie DM, Gans BM, Gatens PF, Leonard JA, McPhee MC, Lippincott JB: Rehabilitation Medicine: Principle and Practice. 2nd edition. Philadelphia: J. B. Lippincott Company; 1993.

23. Komi PV: Stretch-shortening cycle. In Strength and Power in Sport. Oxford: Blackwell Scientific Publications; 1992:230-238.

24. Winter DA: Biomechanics and Motor Control of Human Gait: Normal, Elderly and Pathological. 2nd edition. New York: Wiley; 1991.

25. Müller R, Bisig A, Kramers I, Stüssi E: Influence of stair inclination on muscle activity in normals. J Biomech 1998, 31(1):32-32(1).

26. Riener R, Rabuffetti M, Frigo C: Stair ascent and descent at different inclinations. Gait Posture 2002, 15(1):32-44.

27. Luchies CW, Alexander NB, Schultz AB, Ashton-Miller J: Stepping responses of young and old adults to postural disturbances: kinematics. J Am Geriatr Soc 1994, 42(5):506-512.

28. Mcllroy WE, Maki BE: Age-related changes in compensatory stepping in response to unpredictable perturbations. J Gerontol 1996, 51 (6):289-296. M.

29. Lu CL, Yu B, Basford JR, Johnson ME, An KN: Influences of cane length on the stability of stroke patients. J Rehabil Res Dev 1997, 34(1):91-100.

doi:10.1186/1880-6805-33-36

Cite this article as: $\mathrm{Li}$ and Chou: The effect of cane length and step height on muscle strength and body balance of elderly people in a stairway environment. Journal of Physiological Anthropology 2014 33:36. 